Condensed Matter Physics, 1999, Vol. 2, No. 1(17), p. 149-154

GOJDEMSED

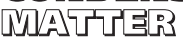

PINTSESS

\title{
Ising-type behaviour of critical properties in weak ferroelectric $\mathrm{Li}_{2} \mathrm{Ge}_{7} \mathbf{O}_{15}$
}

\author{
A.Yu.Kudzin, M.D.Volnianskii, M.P.Trubitsyn, I.A.Bsoul \\ Dnipropetrovsk State University, \\ 13 Naukova Str., 320625 Dnipropetrovsk, Ukraine
}

Received January 20, 1998

\begin{abstract}
The dielectric constant $\varepsilon$ and electron spin resonance spectra of $\mathrm{Mn}^{2+}$ ions have been studied in the range of the ferroelectric phase transition in $\mathrm{Li}_{2} \mathrm{Ge}_{7} \mathrm{O}_{15}$ single crystals. Analysis of the experimental data permits one to estimate the critical exponents of dielectric susceptibility $\gamma \cong 1.25$, order parameter $\beta \cong 0.32$ and correlation length $\nu \cong 0.63$. The values of the critical exponents determined in a fairly broad temperature interval around $\mathrm{T}_{\mathrm{c}}$, are consistent with the theoretical predictions of the Ising model with a one-component non-polar ordering coordinate.
\end{abstract}

Key words: weak ferroelectric, dielectric constant, electron spin resonance

PACS: $77.80 . \mathrm{Bh}$

\section{Introduction}

In $\mathrm{Li}_{2} \mathrm{Ge}_{7} \mathrm{O}_{15}$ crystals, hereafter abbreviated as LGO, a second order transition from the paraelectric phase (space group $\mathrm{D}_{2 h}^{14}$ ) to the ferroelectric one (space group $\mathrm{C}_{2 \nu}^{5}$ ) occurs at temperature $\mathrm{T}_{\mathrm{c}}=283.5 \mathrm{~K}[1,2]$. The phonon mode, becoming soft on approaching $\mathrm{T}_{\mathrm{c}}$, was observed by the Raman scattering [3] and submillimeter spectroscopy [4]. As it was emphasized in [4], the soft mode is characterized by an extremely small effective charge and its contribution to the dielectric constant anomaly does not exceed $10 \%$ of the magnitude of $\varepsilon$ peak at $\mathrm{T}_{\mathrm{c}}$. Dielectric investigations, carried out in the $21 \mathrm{MHz} \div 7 \mathrm{GHz}$ frequency range [5], have revealed that another mode of a relaxational type becomes dominant near the transition point and gives the main contribution to $\varepsilon$ anomaly. In accordance with X-Ray data [1], the structure of LGO crystals is formed by $\left(\mathrm{GeO}_{4}\right)$ and $\left(\mathrm{GeO}_{6}\right)$ polyhedral frameworks, whereas $\mathrm{Li}^{+}$ions are positioned in structural channels. The neutron diffraction study [6] allows one to associate the cooperative tilting motion of the $\left(\mathrm{GeO}_{4}\right)$ tetrahedrons with oscillator-type dynamics and shows that the motion of 
$\mathrm{Li}^{+}$ions along the channels direction has a relaxational nature.

So, the physical properties of LGO crystals are characterized by a combination of the features usually attributed to displacive and order-disorder types of structural phase transitions. It seems that previous attempts to describe the temperature behaviour of the LGO dielectric constant [7] and the central peak intensity in hyper-Raman experiment [8] on the basis of the mean field approximation can be specified.

This paper reports the results of the dielectric constant $\varepsilon$ and ESR measurements carried out in the range of the LGO phase transition.

\section{Dielectric data}

The studied LGO monocrystals were grown from the melt by the Chokhralsky method. The samples used in dielectric experiments were prepared as the plates of characteristic dimensions $10 \times 6 \times 1.6 \mathrm{~mm}^{3}$ with the polar axes $\bar{c}$ perpendicular to the largest plane. The dielectric measurements were performed at $1 \mathrm{kHz}$ in the interval $273 \div 303 \mathrm{~K}$ at cooling. The temperature was changed with the rate $~$ $0.2 \mathrm{~K} / \mathrm{min}$ and controlled with the accuracy $0.02 \mathrm{~K}$. The dielectric constant was measured with a precision higher than $10^{-3}$.

The temperature behaviour $\varepsilon(\mathrm{T})$ in the range of the transition point is represented in the insert to figure 1 . The dielectric constant demonstrates a wellpronounced $\lambda$-shaped anomaly and reaches its maximal value $\sim 300$ at $\mathrm{T}^{*}=$ $283.92 \mathrm{~K}$. The magnitude and sharpness of the $\varepsilon$ peak manifests a much better quality of the investigated monocrystals in comparison with LGO samples studied in [7]. Since the dielectric constant below $\mathrm{T}_{\mathrm{c}}$ may be affected by such artifacts as the domain walls motion, mobile imperfections effects etc., our attention is focused on the analysis of the $\varepsilon(\mathrm{T})$ behaviour in a paraelectric phase.

At first we try to describe the dependence $\varepsilon(\mathrm{T})$ within the framework of the Landau theory. The expression of the Curie-Weiss type

$$
\varepsilon=\varepsilon_{0}+\frac{C}{\left(T-T_{\mathrm{c}}\right)},
$$

with three parameters - background $\varepsilon_{0}$, Curie-Weiss constant $\mathrm{C}$ and transition temperature $\mathrm{T}_{\mathrm{c}}$, is fitted by the least square method to the experimental data. The calculations are performed in the interval $T^{*} \leqslant T<296 \mathrm{~K}$ since above $296 \mathrm{~K}$ the dielectric constant varies very slowly and the real behaviour $\varepsilon(\mathrm{T})$ is masked by experimental precision. The fitting procedure yields the following values:

$$
\varepsilon_{0}=10.8 ; C=3.5 \mathrm{~K} ; T_{\mathrm{c}}=283.93 \mathrm{~K}
$$

with the relative mean square error $\sigma=0.16$. An attempt to take into account the possible drift of the background dielectric constant and to represent it as $\varepsilon_{0}=\varepsilon_{0}^{\prime}+p T$ does not decrease the $\sigma$ value.

Further, the experimental data are fitted by the exponential expression 


$$
\varepsilon=\varepsilon_{0}+A\left(T-T_{\mathrm{c}}\right)^{-\gamma},
$$

including additional parameter $\gamma$. The values calculated in the interval $T^{*} \leqslant T<$ $296 \mathrm{~K}$ are as follows:

$$
\varepsilon_{0}=11.0 ; A=3.3 \mathrm{~K}^{\gamma} ; \gamma=1.25 ; T_{\mathrm{c}}=283.90 \mathrm{~K}
$$

with $\sigma=5.8 \times 10^{-2}$.

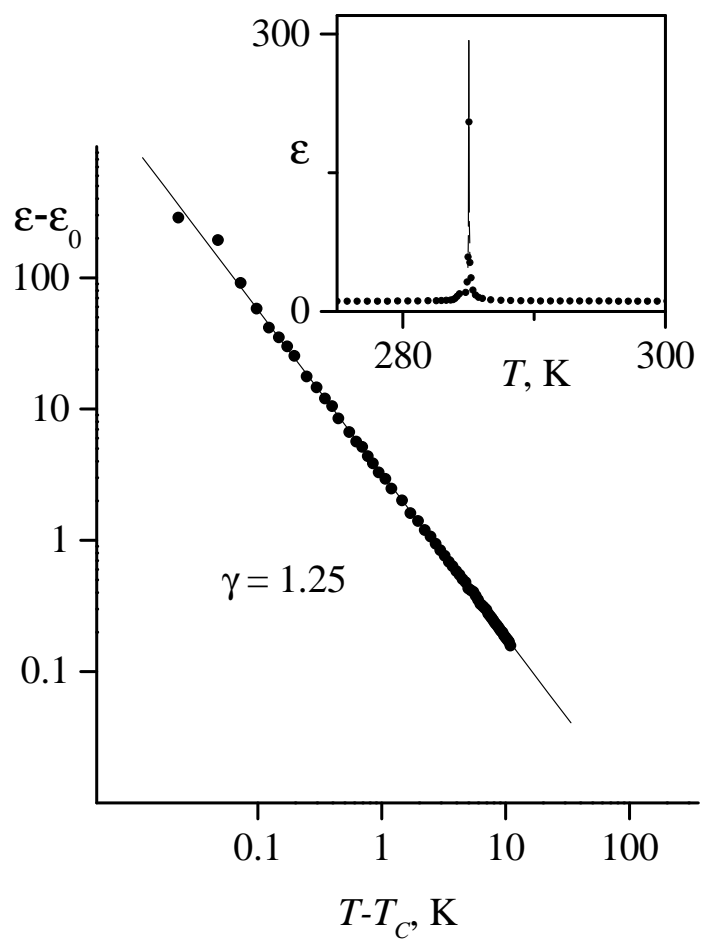

Figure 1. Dielectric constant $\left(\varepsilon-\varepsilon_{0}\right)$ versus $\left(T-T_{\mathrm{c}}\right)$ in a log-log scale $\left(T>T_{\mathrm{c}}\right)$. In the insert: dependence $\varepsilon(T)$ around $T_{\mathrm{c}}$ in an ordinary scale.

The obtained results clearly show that an assumption of a non-classical exponential behaviour (2) decreases the mean square error $\sigma$ in approximately three times in comparison with the classical Curie-Weiss expression (1). Besides, the use of (2) gives a more reliable value of the transition point, whereas parameter $T_{c}$, obtained on the basis of the Curie-Weiss law (1), is higher than temperature $\mathrm{T}^{*}$ of the dielectric peak and hence slightly exceeds the real transition point.

So, it may be concluded that exponential expression (2) with a nonclassical value of $\gamma$ gives a better fit to the experimental data than the Landau theory. The temperature dependence of $\left(\varepsilon-\varepsilon_{0}\right)$ versus $\left(T-T_{\mathrm{c}}\right)$, represented in figure 1 in a log-log scale, satisfactorily corresponds to a straight line with slope $\gamma \cong 1.25$ in the interval considered.

It seems important to support the conclusion about the non-classical behaviour of the dielectric constant in

LGO by alternative experimental techniques. In the next section we report some results of the electron spin resonance investigations of the ferroelectric phase transition in LGO.

\section{Radiospectroscopic data}

The ESR spectra were studied in LGO monocrystals doped with $\mathrm{Mn}^{2+}(0.06 \%$; $0.2 \%$ wt) ions. The samples were cut as $3 \times 3 \times 4 \mathrm{~mm}^{3}$ parallelepipeds with sides parallel to the main crystallographic planes. The spectra were measured on a conventional X-band spectrometer Radiopan SE/X 2547 equipped with a liquid nitrogen gas flow system. The localization of paramagnetic ions in the LGO lattice 
was determined on the basis of angular dependencies of $\mathrm{Mn}^{2+}$ spectra. The data reported earlier [9] give evidence that $\mathrm{Mn}^{2+}$ centers substitute $\mathrm{Li}^{+}$ions in broad channels of the LGO structure with non-local compensation of the excess charge of the probe. It should be noted that the $\mathrm{Mn}^{2+}$ probe preserves the point symmetry of the host ion and, hence, does not drastically perturb the surroundings. So, one may hope, that ESR of manganese adequately reflects the critical properties of the perfect LGO structure.

In an ESR experiment, the information about statical and dynamical phenomena accompanying the structural phase transition can be obtained by measuring the ESR line position, width and shape. As it was shown in [10], on approaching $\mathrm{T}_{\mathrm{c}}$ from above, the resonance lines of $\mathrm{Mn}^{2+}$ broaden and split into doublets in the ferroelectric phase.

The line splitting, observed below $\mathrm{T}_{\mathrm{c}}$, results from the correlated atomic distortions within a range of the paramagnetic probe. The local shift of the splitted resonance lines with temperature variations in the ferrophase is induced by the local order parameter and, consequently, reflects its magnitude. It may be shown that the distance $\Delta \mathrm{H}$ between splitted spectral components is proportional to the local order parameter $\eta_{\text {loc }}$. So, measuring $\Delta \mathrm{H}(\mathrm{T})$ allows one to investigate the temperature behaviour of $\eta_{\text {loc }}$. The dependence of $\Delta \mathrm{H}$ versus $\left(\mathrm{T}_{\mathrm{c}}-\mathrm{T}\right)$ is represented in figure 2 in a $\log$-log scale. It is quite clear that the experimental behaviour in the interval $T_{\mathrm{c}}-10 \mathrm{~K} \leqslant T<T_{\mathrm{c}}$ may be described by a straight line with the mean slope $\beta \cong 0.32$, which appreciably differs from the classical value of the order parameter critical exponent 0.5 . The dependence $\Delta \mathrm{H}^{2}\left(\mathrm{~T}_{\mathrm{c}}-\mathrm{T}\right)$, represented in the insert to figure 2 , demonstrates that the local order parameter behaviour significantly deviates from the Landau theory predictions in the low temperature vicinity of the transi-

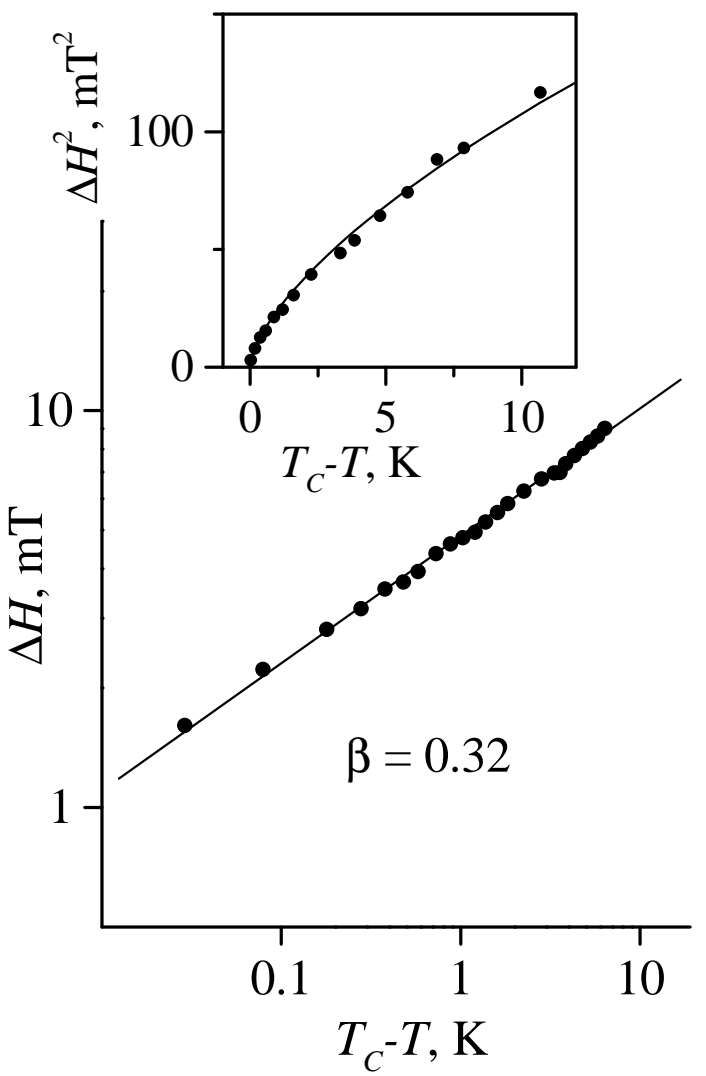

Figure 2. ESR line splitting $\Delta H$ versus $\left(T_{\mathrm{c}}-T\right)$ in a log-log scale. In the insert: dependence $\Delta H^{2}\left(T_{\mathrm{c}}-T\right)$ demonstrating deviation of the experimental behaviour from the Landau theory. tion point.

As it was mentioned above, the ESR lines anomalously broaden around $\mathrm{T}_{\mathrm{c}}$. The analysis of ESR spectra transformation via the phase transition shows that line width broadening is determined by inhomogeneous mechanisms and contributed by 
the local order parameter fluctuations $\delta \eta_{l o c}[10]$. Simulating the experimental line shape, we derived the critical contribution to the line width $\delta \mathrm{H}_{C R}$ and separated it from unessential background. The critical ESR line width dependence $\delta \mathrm{H}_{\mathrm{CR}}(\mathrm{T})$, measured on approaching $\mathrm{T}_{\mathrm{c}}$ from above, is represented in a double logarithmic scale in figure 3 . It can be seen that in the interval $T_{\mathrm{c}}+1 \mathrm{~K} \leqslant T \leqslant T_{\mathrm{c}}+20 \mathrm{~K}$ the experimental behaviour satisfactorily agrees with the exponential law $\delta \mathrm{H}_{\mathrm{CR}} \sim(\mathrm{T}$ $\left.\mathrm{T}_{\mathrm{c}}\right)^{-\nu}$. The mean slope of the $\delta \mathrm{H}_{\mathrm{CR}}\left(\mathrm{T}-\mathrm{T}_{\mathrm{c}}\right)$ dependence in this interval permits one to estimate the critical index of the correlation length $\nu \cong 0.63$. In the narrow interval $\sim 1 \mathrm{~K}$ above $\mathrm{T}_{\mathrm{c}}$ the dependence of the critical line width deviates from a straight line and tends to saturation (figure 3 ). This deviation may be interpreted as the result of partial suppression of local order parameter fluctuations by longrange dipole-dipole interactions.

\section{Conclusions}

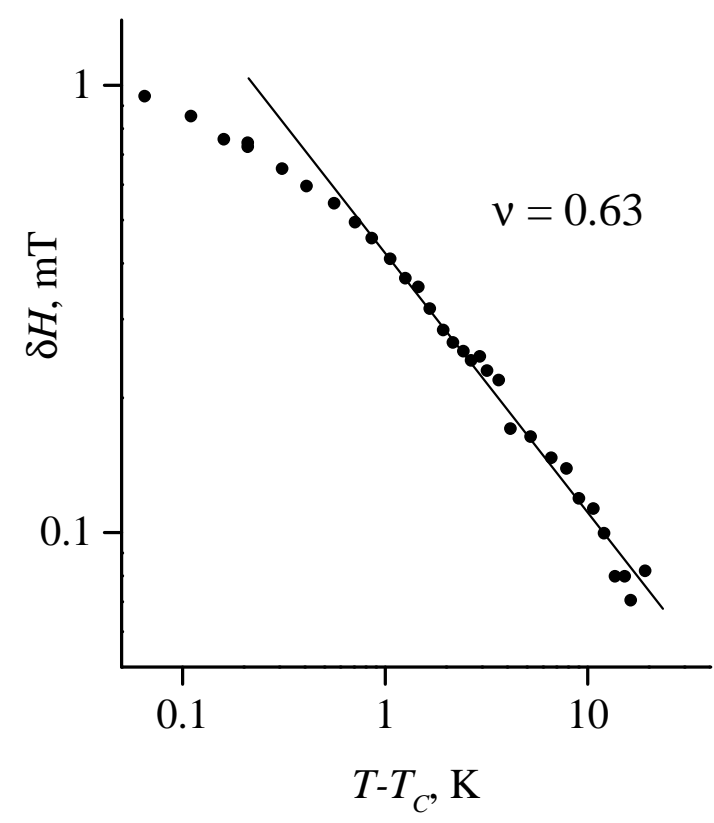

Figure 3. Temperature dependence of critical contribution to the ESR line width in a log-log scale.
Investigations of the dielectric constant and $\mathrm{Mn}^{2+}$ ESR spectra near the ferroelectric phase transition in LGO crystals allow one to determine the values of three critical indexes: the exponent of dielectric susceptibility $\gamma \cong$ 1.25 , order parameter $\beta \cong 0.32$ and correlation length $\nu \cong 0.63$. It is remarkable that the values of the critical exponents obtained in a fairly broad temperature range of $T_{c}$ via studying the macroscopic and local properties are consistent with each other and correspond to the theoretical values given by a three-dimensional Ising model with a one-component non-polar ordering coordinate. Obviously, an extremely small soft mode effective charge predetermines the Ising-type behaviour of the LGO critical properties. Dipoledipole interactions, mainly determining critical phenomena in classical uniaxial ferroelectrics, are no longer a decisive factor in LGO crystals. Consequently, order parameter fluctuations are well pronounced in a broad interval around $\mathrm{T}_{\mathrm{c}}$ and lead to characteristic features peculiar to the order-disorder structural phase transition. 


\section{References}

1. Volenkle H., Wittman F., Nowotny H., Die kristallstruktur des lithiumhepttagermanats $\mathrm{Li}_{2} \mathrm{Ge}_{7} \mathrm{O}_{15}$. // Monatsh. Chem., 1970, vol. 101, p. 46-56.

2. Haussuhl S., Wallrafen F., Recker K., Eckstein J. Growth, elastic properties and phase transition of ortorombic $\mathrm{Li}_{2} \mathrm{Ge}_{7} \mathrm{O}_{15}$. // Z. Kristallogr., 1980, vol. 153, p. 329-337.

3. Wada M. Soft mode spectroscopic study of ferroelectric phase transition in $\mathrm{Li}_{2} \mathrm{Ge}_{7} \mathrm{O}_{15}$. // Indian J. of Pure \& Appl. Phys., 1988, vol. 26, No. 2, p. 68-71.

4. Volkov A., Kozlov G., Goncharov Yu. Observation of the soft polar mode in the paraelectric phase in $\mathrm{Li}_{2} \mathrm{Ge}_{7} \mathrm{O}_{15}$. // Journ. Phys. Soc. Jap., 1985, vol. 54, No. 2, p. $818-821$.

5. Horioka M., Sawada A., Wada M. Dielectric critical slowing-down in ferroelectric $\mathrm{Li}_{2} \mathrm{Ge}_{7} \mathrm{O}_{15}$. // Journ. Phys. Soc. Jap., 1989, vol. 58, No. 10, p. 3793-3797.

6. Iwata J., Koyani N., Shibuya I., Wada M., Sawada A., Ishibashi Y. Neutron diffraction study of structural phase transition in ferroelectric $\mathrm{Li}_{2} \mathrm{Ge}_{7} \mathrm{O}_{15}$. // J. Phys. Soc. Jap., 1987, vol. 56, No. 7, p. 2420-2427.

7. Wada M., Ishibashi Y. Ferroelectric phase transition in $\mathrm{Li}_{2} \mathrm{Ge}_{7} \mathrm{O}_{15}$. // Journ. Phys. Soc. Jap., 1983, vol. 52, No. 1, p. 193-199.

8. Morioka Y., Wada M., Sawada A. Hyper-Raman study of ferroelectric phase transition in $\mathrm{Li}_{2} \mathrm{Ge}_{7} \mathrm{O}_{15}$. // Journ. Phys. Soc. Jap., 1988, vol. 57, No. 9, p. 3198-3203.

9. Trubitsyn M.P., Volnianskii M.D., Kudzin A.Yu. EPR of $\mathrm{Mn}^{2+}$ ions in lithium heptagermanate crystals. // Kristallographia, 1991, vol. 36, No. 6, p. 1472-1476 (in Russian).

10. Trubitsyn M.P., Volnianskii M.D., Kudzin A.Yu. EPR line width broadening near ferroelectric phase transition in $\mathrm{Li}_{2} \mathrm{Ge}_{7} \mathrm{O}_{15}: \mathrm{Mn}^{2+}$ crystals. // Fiz. Tverd. Tela, 1992, vol. 34, No. 6, p. 1746-1752 (in Russian).

\section{Ізінгівська поведінка критичних властивостей слабкого сегнетоелектрика $\mathrm{Li}_{2} \mathrm{Ge}_{7} \mathrm{O}_{15}$}

\section{А.Ю.Кудзін, М.Д.Волнянський, М.П.Трубіцин, І.А.Бусоул}

Дніпропетровський державний університет, 320625 Дніпропетровськ, пров. Науковий, 13

Отримано 20 січня 1998 р.

Діелектрична проникність $\varepsilon$ та спектри ЕПР іонів $\mathrm{Mn}^{2+}$ досліджені в околі сегнетоелектричного фазового переходу у кристалах $\mathrm{Li}_{2} \mathrm{Ge}_{7} \mathrm{O}_{15}$. Аналіз експериментальних даних дозволив оцінити критичні індекси діелектричної сприйнятливості $\gamma \simeq 1.25$, параметра порядку $\beta \simeq 0.32$ і кореляційної довжини $\nu \simeq 0.63$. Величини критичних індексів, обчислені у досить широкому інтервалі температур поблизу $\mathrm{T}_{\mathrm{c}}$, узгоджуються з теоретичними показниками моделі Ізінга для однокомпонентного неполярного параметра порядку .

Ключові слова: слабкий сегнетоелектрик, діелектрична константа, електронний парамагнітний резонанс.

PACS: $77.80 . B h$. 